\title{
Ausencia del padre y orfandad masculina: Notas sobre Pedro Páramo
}

Fatherlessness and Male Orphanhood: Notes on Pedro Páramo

\author{
A paternidade e a orfandade masculina: Notas \\ sobre Pedro Páramo
}

\author{
Rocío García-Rey \\ Universidad Nacional Autónoma
}

México

Recibido: 17/4/2021 - Aceptado: 13/5/2021

\begin{abstract}
Resumen
Pedro Páramo es una novela fundamental de la literatura contemporánea en el ámbito hispanoamericano. El inicio proporciona la clave del periplo del hijo abandonado que va a buscar al padre ausente; el hombre cuya única claridad es su ausencia, su abandono. Es una búsqueda transformada en historia de un duelo no resuelto, un dolor que el hijo acumulará sin entender que la ausencia del padre es la presencia de la misma muerte. Me centraré en el ejercicio de interpretar la obra literaria desde la creación y recreación del lenguaje y de los temas, para seguir escudriñando "rutas de interpretación" en el sentido propuesto por Wolfgang Iser. El comentario con respecto al tópico de Pedro Páramo lo haré en clave de los estudios de género, particularmente, de aquellos planteamientos de la estudiosa chilena Sonia Montesinos.
\end{abstract}

Palabras clave: Pedro Páramo, literatura contemporánea latinoamericana, Juan Rulfo, género, Sonia Montesinos.

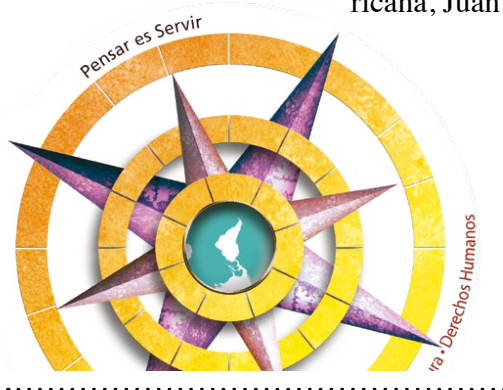

Abstract

Pedro Páramo is a key novel in contemporary Hispanic American literature. The beginning provides the key to the journey of the abandoned son who goes in search of the 
absent father; the man whose only clarity is his absence, his abandonment. It is a search transformed into a story of unresolved grief, a pain that the son will accumulate without understanding that the absence of the father is the presence of death itself. I will focus on the exercise of interpreting the literary work from the creation and re-creation of language and themes, to continue exploring "routes of interpretation" in the sense proposed by Wolfgang Iser. I will comment on the topic of Pedro Páramo from the point of view of gender studies, particularly, those of the Chilean scholar Sonia Montesinos.

Keywords: Pedro Páramo, contemporary Latin American literature, Juan Rulfo, gender, Sonia Montesinos.

Resumo

Pedro Páramo é um romance fundamental na literatura hispano-americana contemporânea. $\mathrm{O}$ início fornece a chave para a viagem do filho abandonado que vai em busca do pai ausente; o homem cuja única clareza é sua ausência, seu abandono. É uma busca transformada em uma história de dor não resolvida, uma dor que o filho acumulará sem compreender que a ausência do pai é a própria presença da morte. Vou me concentrar no exercício de interpretação da obra literária a partir da criação e recriação de linguagem e temas, a fim de continuar examinando "rotas de interpretação" no sentido proposto por Wolfgang Iser. Comentarei o tópico de Pedro Páramo a partir da perspectiva dos estudos de gênero, particularmente as abordagens da estudiosa chilena Sonia Montesinos

Palavras chave: Pedro Páramo, literatura latino-americana contemporânea, Juan Rulfo, género, Sonia Montesinos.

Pedro Páramo es una novela fundamental de la literatura contemporánea en el ámbito hispanoamericano. Fue publicada en 1955 y cabe recordar que, en su momento, no tuvo la aceptación unánime de sus lectores. En palabras de Carlos Fuentes (s/f):

Todos estos reproches partían de concepciones unánimes de la novela como unidad de personajes, argumento y estilo. La elipsis narrativa de Rulfo desconcertaba a los críticos y lectores de novelas "bien hechas", es decir, adheridas a la lógica y sin resquicio de misterio. La cercanía de Pedro Páramo a la forma poética enajenaba, también, a críticos y lectores acostumbrados a novelas que lo eran porque, a la manera de Zola, describían detalladamente muebles, calles, carnicerías y burdeles... (http:// www.proceso.com.mx/486897/ sobre-pedro-paramo) 
Estos reproches se entienden a la luz de nuevas lecturas que permiten interpretar la obra literaria desde la creación y recreación tanto del lenguaje como de los temas. Es en el segundo punto en el que me centraré para seguir escudriñando "rutas de interpretación", como las llama Wolfgang Iser (2000), con respecto a la obra rulfiana.

El comentario en cuanto al tópico de Pedro Páramo lo haré en clave de los estudios de género, particularmente, de aquellos planteamientos de Sonia Montesinos vertidos en el libro Madres y huachos. Alegorías del mestizaje chileno. ¿Qué tiene que ver el postulado acerca de la cultura chilena con la obra de Rulfo? La relación la podemos hallar rápidamente, si nos concentramos en el inicio de la novela. Es este comienzo el que nos proporciona la base del periplo del hijo abandonado que va a buscar al padre ausente; al hombre cuya única claridad es su ausencia, su abandono: "Vine a Comala porque me dijeron que acá vivía mi padre, un tal Pedro Páramo”.

Con el inicio se abre el periplo de la búsqueda transformada en historia de un duelo no resuelto, un dolor que el hijo acumulará sin entender que la ausencia del padre es la presencia de la misma muerte. Es preciso prestar atención, además, en los tiempos verbales utilizados en ese comienzo: Vine y dijeron corresponden al pasado perfecto simple, utilizado para las acciones finiquitadas; estos verbos conjugados se enfrentan al copretérito, el cual "indica que una acción pasada es de carácter duradero o sin límites precisos" (http://dem.colmex. mx/repository/pdfs/0041-44TiemposVerbales.pdf). Por ello, "vivía" marcará la esperanza de hallar al padre, encontrarlo porque el hijo ha vivido cobijado solo bajo la sombra mariana de su madre. En efecto, como Navarrete González (s/f) lo señala, "por asociación metafórica, la virgen se entendería como figura de mujer latinoamericana (huacha madre) capaz de limpiar y salvar tanto el dolor como la vergüenza del sometimiento acarreado por el bastardaje" (https:// webs.ucm.es/info/especulo/numero29/huacha.html)

"Todos somos hijos de Pedro Páramo" se lee en la novela, lo que implica el bastardaje simbólico, circunstancia de un cúmulo de hombres que no fueron asimilados por la figura paterna $y$, por eso mismo, tal figura es la gran "ánima” que nunca acunó a los hijos. Estos últimos fueron sostenidos 
- como en la iconografía occidental podemos verlo - únicamente por la madre, también, abandonada. Así como en obras por demás canónicas, varios son los personajes hombres que cargan a cuestas el dolor acallado (pensemos, si deseamos ubicar a uno de estos en Ulises cuya cicatriz al final solo pudo ser reconocida por Euriclea); en Pedro Páramo, la pena que pesa sobre todo es la de Juan Preciado, quien busca, aunque sea los esqueletos, para poder armar completamente su identidad.

El hijo olvidado carga una doble herida - no cicatriz - , la del abandono hacia el binomio madre-hijo. Juan Preciado, por ende, guarda con sumo cuidado las palabras de la madre:

- No vayas a pedirle nada. Exígele lo nuestro. Lo que estuvo obligado a darme y nunca me dio... El olvido en que nos tuvo mi hijo, cóbraselo caro.

- Así lo haré madre.

Bajo la óptica de Montesinos, el padre ausente es la herencia del conquistador (también ausente). Cuando el hijo quiere tener una primera "fotografía" del tal Pedro Páramo, como lo llama, se encuentra ante la respuesta "Pedro Páramo es un rencor vivo". Esta es una segunda clave, si consideramos que el copretérito ahora ha sido desplazado por un presente. Encontramos la oración armada de la siguiente manera:

Es (verbo) + un (artículo indefinido) + rencor (sustantivo) + vivo (adjetivo).

Es entonces que el juego retórico de la tesis/antítesis unido al juego oximorónico proporciona al lector la pauta para asumir que la novela es un entramado, una yuxtaposición entre Eros y Tánatos. Tánatos está presente desde el mismo título, porque Pedro significa piedra, que aquí bien podemos extrapolar a la imagen de tumba, y Páramo es “Terreno llano, yermo, desabrigado, y generalmente elevado". Se trata de un personaje que encarna la diégesis misma, la muerte con su principal correlato: la ausencia y su persistente resentimiento. Lo único vivo es la hostilidad y la certeza que lanza a sus hijos de no haber estado más que como un rumor.

¿Cómo hallar al padre doblemente ausente? ¿Cómo entender que se ha llegado al lugar indicado por la madre y se halle el inexorable aserto "Pedro Páramo murió hace muchos años"? La salida y entrada al mismo tiempo es seguir sumergiéndose en el mundo onírico, en un tiempo

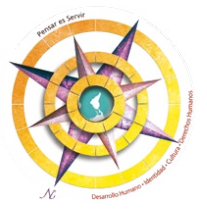


irreal, en el que, como en los sueños, es posible empalmar tiempos. Juan Preciado, así, sigue su periplo de muerto viviente, pues tiene el arraigo a la madre, pero la identidad del padre es un obstáculo para entender quién es en su totalidad. Aunado a lo dicho, es importante señalar cómo Juan Preciado, el huérfano de padre, hace la defensa a ultranza de la madre.

— Tu padre ha muerto - le dijo.

Y luego, como si se le hubieran soltado los resortes de su pena, se dio vuelta sobre sí misma una y otra vez, una y otra vez, hasta que unas manos llegaron hasta sus hombros y lograron detener el rebullir de su cuerpo.

[...] otra vez el llanto suave pero agudo, y la pena haciendo retorcer su cuerpo.

- Han matado a tu padre.

- ¿Y a ti quién te mató madre?

La madre murió asfixiada de abandono, sin sentirse legitimada; por esto, lo único que puede heredar al hijo son los recuerdos, esos que son la gran cadena para enlazar todo el correlato de la novela: la desolación, la tristeza. Incluso, el otro personaje clave femenino, Susana San Juan, solo puede ser consolada por su padre con el desconsuelo: "Déjame consolarte con mi desconsuelo". Es entonces, que nuevamente también nos enfrentamos al juego de opuestos, al juego oximorónico que adquiere lógica en un mundo donde todo es muerte y lo único vivo es la memoria que cruza postales ora de anhelos, ora de la "Media Luna".

La gran prolepsis, hemos dicho en el título mismo, no implica que sigan apareciendo claves totalmente literarias a lo largo del texto. Susana San Juan, quien pareciera estar más en la balanza de Eros, es presentada en una escena.

— ¡Dame lo que está allí Susana!

Y ella agarró la calavera entre sus manos y cuando la luz le dio de lleno la soltó.

—Es una calavera de muerto - dijo.

- Debes encontrar algo más junto a ella. Dame todo lo que encuentres.

El cadáver se deshizo en canillas; la quijada se desprendió como si fuera de azúcar. [...] Y la calavera primero; aquella bola redonda que se deshizo entre sus brazos.

Ese es el mundo en que Rulfo, después de haber leído La amortajada, de la chilena María Luisa Bombal, 
crea para los lectores. Se trata de un universo en el que el eje es la piedra tumba que no terminó, en términos figurados, de escribir en su epitafio el nombre de todos sus hijos; uno en el que el gran panteón que es la Media Luna es el topos, donde se ubica el otro correlato de la historia: "El hueco simbólico del Pater", como lo ha llamado Montesinos (2017): "Pensamos en el hueco simbólico del Pater, en el imaginario mestizo de América Latina, será sustituido por una figura masculina poderosa y violenta [...] El padre ausente se troca así en la presencia teñida de potestad política, económica y bélica [...]" (http://www.biblioteca.org. ar/libros/151505.pdf)

En Pedro Páramo, sin embargo, la posibilidad de que los hijos huérfanos completen su nombre, una vez que sean conocidos, reconocidos y nombrados por el padre, se diluye, se vuelve polvo. Y es así que la ausencia es perennidad vuelta muerte dibujada, fotografiada con palabras.

El padre es inaccesible porque ha estado en el mundo de Tánatos. Leamos el final de la novela: "Se apoyó en los brazos de Damiana Cisneros e hizo intento de caminar. Después de unos cuantos pasos cayó, suplicando por dentro, pero sin decir una sola palabra. Dio un golpe seco contra la tierra y se fue desmoronando como si fuera un montón de piedras".

Un hombre no puede, bajo las construcciones culturales, suplicar públicamente; por este motivo, es tan importante ver cómo funciona el gerundio: suplicando más por dentro. Se trata de la locución adverbial que nos da a conocer que Pedro Páramo también fue la herencia de la orfandad multiplicada en el mundo de los muertos. Quizá mimesis de tantos hombres que, sin entenderlo, solo vivieron bajo el resguardo de la madre, porque el padre lo único que deja es la impronta del dolor y el rechazo.

\section{Referencias}

Fuentes, C.(s.f.). Sobre Pedro Páramo. Recuperado de http://www.proceso.com. mx/486897/sobre-pedro-paramo

Iser, W. (2000). Rutas de interpretación. Ricardo Rubio Ruiz, trad. México: FCE.

Montesinos, S. (2017). Madres y huachos. Alegorías del mestizaje chileno. Chile: Catalonia Ed.

Navarrete, C. (s. f.). La circularidad identitaria de la huacha, en Madres y huachos. Alegorías del mestizaje chileno. Recuperado de https://webs.ucm. es/info/especulo/numero29/huacha. html 